\title{
The Mediating Effect of Fatigue on Work-Life Balance and Positive Well-Being in Railway Staff
}

\author{
Jialin Fan, Andrew P. Smith \\ Centre for Occupational and Health Psychology, School of Psychology, Cardiff University, Cardiff, UK \\ Email: FanJ12@Cardiff.ac.uk, SmithAP@Cardiff.ac.uk
}

How to cite this paper: Fan, J.L. and Smith, A.P. (2018) The Mediating Effect of Fatigue on Work-Life Balance and Positive Well-Being in Railway Staff. Open Journal of Social Sciences, 6, 1-10. https://doi.org/10.4236/jss.2018.66001

Received: January 31, 2018

Accepted: May 20, 2018

Published: May 23, 2018

\begin{abstract}
Both fatigue and negative work-life balance can be influenced by job characteristics and individual differences, while fatigue is associated with reduced positive well-being. This paper reports a study that investigated the mediation effect of fatigue between those stressors and well-being outcomes among UK railway staff. A large number of significant mediation effects of fatigue were found in this study, and as a result, the process by which job demands, job support and control influence major positive well-being outcomes can be partially explained by fatigue.
\end{abstract}

\section{Keywords}

Well-Being, Work-Life Balance, Occupational Fatigue, Employee Happiness, Train Crew

\section{Introduction}

Fatigue is a daily experience among people in the workforce. In the railway industry, fatigue is a serious issue due to the heavy workload, long working hours, and shiftwork. Failure to manage the train crew's fatigue may result in an increased risk to train safety and employees' well-being. The stressors causing occupational fatigue include either job characteristics or personal characteristics [1]. Such stressors also have been found to affect work-life balance and positive well-being [2]. Social support and personality have been found to play buffering roles between fatigue and positive well-being [1]-[6], while job demands and shift work have been found to be associated with a high level of fatigue, negative work-life balance (also called work-life conflict) [1] [7], and impaired positive well-being [8]. Previous studies have demonstrated that fatigue is strongly re- 
lated to well-being dimensions [9] and mediates the effect of physical workload on quality of life [10]. However, the relationship that job and personal characteristics have with fatigue and well-being is unclear.

Cameron [11] has suggested that the term fatigue is synonymous with a generalised stress response over time. This provides the rationale for applying stress models, such as the Demands, Resources, and Individual Effects (DRIVE) model [12], in assessing fatigue. The initial DRIVE model demonstrates the important role of job demand, job resources (i.e., support and control), and individual differences in influencing well-being outcomes (i.e., satisfaction and happiness). Although the model is useful as a manual in studying occupational fatigue, it is too basic in its representation of the workplace-individual stress process. The process described in the initial model lacks the subjective components of perceived stress, while this subjective appraisal may directly or indirectly affect the relationship between the environment and the outcomes.

Therefore, Mark and Smith [12] designed a more complex DRIVE model and proposed an added perceived job stress element (i.e., fatigue). This model mainly proposed that job stress could mediate the impact of job demand, job resources, and individual characteristics on well-being outcomes. It also proposed that individual differences could moderate their relationship between both perceived stress and well-being outcomes. However, subsequent studies [13] [14] [15] [16] have failed to find such a moderating effect, while the mediating effect was not always clear.

Our previous work among train crew found that job characteristics predict work-life balance and well-being (both at work and outside work) as well as occupational fatigue [1] [8]. Such job characteristics affecting both fatigue and well-being include high workload, poor job control and support, exposure to noise and vibration, and shiftwork. These results raised the question as to whether fatigue mediates the impact of work characteristics and individual differences on these outcomes, just as the DRIVE model proposed.

This study aims to examine the relationship that job and personal characteristics have with fatigue, negative work-life balance, and positive well-being, both at work or outside work. It was hypothesised that fatigue was the mechanism through which job characteristics and individual differences would affect well-being outcomes, thus acting as a mediating variable (as shown in Figure 1).

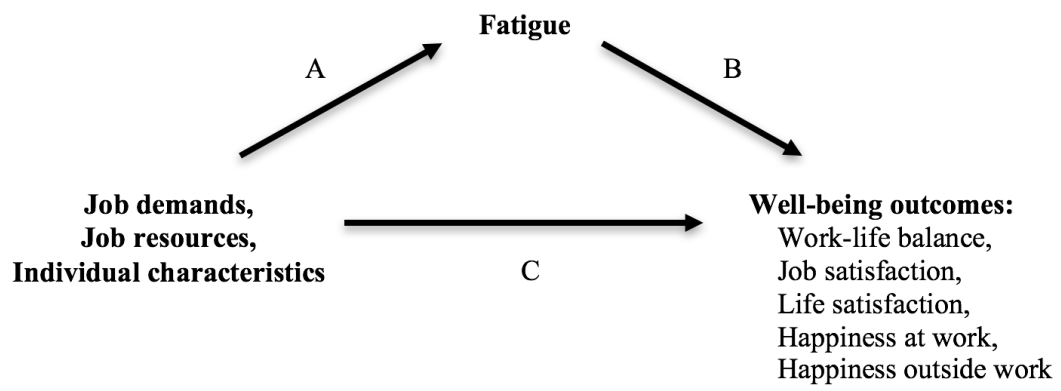

Figure 1. Mediating hypothesis tested. 


\section{Method}

\subsection{Participants}

Participants were recruited from one of the train companies in the United Kingdom. Their job roles included conductors, train drivers, station workers, engineers, administrators, managers, at-seat catering stewards, and controllers.

\subsection{Materials}

This survey ran from 27 April to 18 May, 2015. The well-being questionnaire used in the present study was the Smith Well-being Questionnaire (SWELL), which included26 single-item questions from the Wellbeing Process Questionnaire (WPQ) [5]. It took approximately 15 minutes to complete.

Based on the DRIVE model and WPQ, the items in this survey included individual characteristics, job characteristics, fatigue, and well-being outcomes. The section on job characteristics included job demands, job control and support, working environment (levels of noise and fumes), and whether participants worked in shifts. The section on well-being included positive well-being (i.e., job satisfaction, happiness at work, life satisfaction, and happiness outside work) and work-life balance. Most of the questions were rated on a 10-point scale, and the remaining were Yes/No answers (e.g., "Do you do shift-work?”).

\subsection{Statistical Analyses}

Data analysis was carried out using SPSS 23 software. The independent variables tested were workload, job control and support, shift work, exposure to noise and vibration, exposure to fumes, health-related behaviours (or health lifestyle), and personality. The dependent variables tested were fatigue, negative work-life balance, and positive well-being outcomes. Hayes' [17] PROCESS macro (Model 4) was used to examine whether fatigue mediates the effects of job characteristics and individual differences on outcomes. ANOVA was used to compare the effects of the predictor variables on the outcomes for the high/low fatigue groups.

\section{Results}

\subsection{Descriptive Statistics}

A total of 1067participants completed the questionnaires $(\mathrm{N}=1067$, mean $( \pm \mathrm{SD})$ age $=44.25 \pm 10.763 \mathrm{yr}$.), with a response rate of around $50 \%$. The most common job types were conductors (25.9\%), train drivers (22.6\%), and station workers $(21.3 \%)$. Of the participants, $58.3 \%$ rated their fatigue as high (threshold $=6$ ), and the fatigue problem was apparent in all the job roles mentioned. In addition, $74.9 \%$ of the participants did shiftwork.

\subsection{Correlation}

The association between predictors, fatigue, and well-being outcomes was investigated using the Pearson correlation. High job demands showed a significant 
correlation with fatigue $(\mathrm{r}(1061)=.43, \mathrm{p}<0.01)$, negative work-life balance $(\mathrm{r}$ $(1059)=0.31, \mathrm{p}<0.01$ ), and positive well-being outcomes ( $\mathrm{r}$ from -0.19 to $-0.07, \mathrm{p}<0.01)$. Other negative job characteristics, such as shiftwork, exposure to noise, and exposure to fumes, were also significantly correlated with fatigue and negative work-life balance, with correlation coefficients between .30 and .43 and all significant to $\mathrm{p}<0.01$. No significant correlation was found between shiftwork, work exposure to noise or fumes, and the well-being outside work.

A higher level of job control and support showed a significant negative correlation with a higher level of fatigue and poorer work-life balance ( $\mathrm{r}$ from -0.25 to $-0.27 ; \mathrm{p}<0.01$ ). It was also correlated with positive well-being ( $\mathrm{r}$ from 0.13 to $0.62, \mathrm{p}<0.01)$. In addition, positive personal characteristics, such as positive personality and healthy lifestyle, showed a positive correlation with positive well-being outcomes ( $\mathrm{r}$ from 0.14 to $0.62, \mathrm{p}<0.01$ ), and a small but significant negative correlation with fatigue and negative work-life balance ( $\mathrm{r}$ from -0.15 to $-0.10, \mathrm{p}<0.01)$.

Fatigue showed a significant correlation with negative work-life balance, $r$ $(1061)=0.48, \mathrm{p}<0.01$, with a high level of fatigue associated with poor work-life balance. Fatigue showed a significant negative correlation with the positive well-being outcomes, both in general life and at work, including life satisfaction, job satisfaction, life happiness, and work happiness ( $\mathrm{r}$ from -0.23 to $-0.30, \mathrm{p}<$ $0.01)$.

\subsection{Mediation Effect of Fatigue on Well-Being Outcomes}

Hayes Mediation was used to examine whether fatigue mediated the effects of job characteristics and individual differences on well-being outcomes. The variables used in this analysis were original scores, in which shiftwork was the categorical variable, and the rest were continuous variables. Fatigue was found to mediate the impacts of these variables on most of the well-being outcomes. The indirect effect was tested using a bootstrap estimation approach with 1000 samples [18].

Fatigue was found to mediate the impacts of lifestyle and personality on work-life balance and positive well-being outcomes (shown in Table 1 and Table 2). As the confidence interval of these relationships did not contain zero, the indirect effect could be considered significant [17], and fatigue had a mediation effect on them. Fatigue fully mediated the impact of lifestyle on work-life balance. The total effect of lifestyle on negative work-life balance was -0.14 (CI = $-0.23,-0.05, \mathrm{p}<0.001)$, with the direct effect being $-0.05(\mathrm{CI}=0.13, .03, \mathrm{p}>$ $0.05)$. This full mediation suggested that the process by which lifestyle influences negative work-life balance was completely explained, and there was no need to test for further indirect effects. The rest of the relationships between personal characteristics and positive well-being outcomes were partially mediated by fatigue.

The relationships between job demands, job support and control, and outcomes were mediated by fatigue (Table 3 and Table 4). Fatigue was found to 
Table 1. Mediation effects of fatigue for positive lifestyle on well-being outcomes.

\begin{tabular}{|c|c|c|c|c|c|c|}
\hline \multirow{3}{*}{$\mathrm{Y}$} & \multicolumn{3}{|c|}{ X: Positive Lifestyle } & \multicolumn{3}{|c|}{ M: Fatigue } \\
\hline & \multicolumn{3}{|c|}{ Total Effects } & \multicolumn{2}{|c|}{ Direct Effects } & Indirect Effects \\
\hline & $B$ & $C I$ & $B$ & $C I$ & $B$ & $C I$ \\
\hline Life Satisfaction & $0.27^{* * *}$ & {$[0.21,0.33]$} & $0.25^{* * *}$ & {$[0.19,0.31]$} & 0.03 & {$[0.01,0.04]$} \\
\hline Life Happiness & $0.22^{* * *}$ & {$[0.17,0.28]$} & $0.20^{* * *}$ & {$[0.15,0.25]$} & 0.02 & {$[0.01,0.04]$} \\
\hline Job Satisfaction & $0.16^{* * *}$ & {$[0.09,0.22]$} & $0.13^{* * *}$ & {$[0.06,0.19]$} & 0.03 & {$[0.01,0.05]$} \\
\hline Job Happiness & $0.18^{* * *}$ & {$[0.12,0.24]$} & $0.15^{* * *}$ & {$[0.09,0.20]$} & 0.04 & {$[0.02,0.05]$} \\
\hline $\begin{array}{c}\text { Neg. Work-Life } \\
\text { Balance }\end{array}$ & $-0.14^{*}$ & {$[-0.23,-0.05]$} & -0.05 & {$[-0.13,0.03]$} & -00.08 & {$[-0.13,-0.04]$} \\
\hline
\end{tabular}

Table 2. Mediation effects of fatigue for positive personality on well-being outcomes.

\begin{tabular}{ccccccc}
\hline & \multicolumn{3}{c}{ X: Positive Personality } & \multicolumn{3}{c}{ M: Fatigue } \\
\cline { 2 - 7 } Y & \multicolumn{3}{c}{ Total Effects } & & Direct Effects & Indirect Effects \\
\cline { 2 - 7 } & $B$ & $C I$ & $B$ & $C I$ & $B$ & $C I$ \\
\hline Life Satisfaction & $0.60^{* * *}$ & {$[0.54,0.65]$} & $0.57^{* * *}$ & {$[0.52,0.63]$} & 0.0245 & {$[0.02,0.04]$} \\
Life Happiness & $0.60^{* * *}$ & {$[0.56,0.65]$} & $0.58^{* * *}$ & {$[0.54,0.63]$} & 0.0225 & {$[0.01,0.04]$} \\
Job Satisfaction & $0.47^{* * *}$ & {$[0.40,0.53]$} & $0.44^{* * *}$ & {$[0.37,0.51]$} & 0.0305 & {$[0.02,0.05]$} \\
Job Happiness & $0.47^{* * *}$ & {$[0.41,0.53]$} & $0.43^{* * *}$ & {$[0.38,0.49]$} & 0.0388 & {$[0.02,0.06]$} \\
Neg. Work-Life & $-0.24^{* * *}$ & {$[-0.33,-0.14]$} & $-0.13^{* *}$ & {$[-0.22,0.05]$} & -0.1077 & {$[-0.15,0.06]$} \\
Balance & & & & & & \\
\hline
\end{tabular}

${ }^{*} \mathrm{p}<0.05 ;{ }^{* *} \mathrm{p}<0.05 ;{ }^{* * *} \mathrm{p}<0.05 . \mathrm{B}=$ unstandardised coefficient; $\mathrm{CI}=$ confidence interval.

Table 3. Mediation effects of fatigue for positive lifestyle on well-being outcomes.

\begin{tabular}{ccccccc}
\hline & \multicolumn{3}{c}{ X: Job Demands } & \multicolumn{3}{c}{ M: Fatigue } \\
\cline { 2 - 7 } Y & \multicolumn{3}{c}{ Total Effects } & & Direct Effects & \multicolumn{2}{c}{ Indirect Effects } \\
\cline { 2 - 7 } & $B$ & $C I$ & $B$ & $C I$ & $B$ & $C I$ \\
\hline Life Satisfaction & $-0.08^{* *}$ & {$[-0.13,-0.02]$} & 0.02 & {$[-0.04,0.07]$} & -0.09 & {$[-0.12,-0.07]$} \\
Life Happiness & $-0.07^{* *}$ & {$[-0.12,-0.02]$} & 0.02 & {$[-0.03,0.07]$} & -0.09 & {$[-0.12,-0.07]$} \\
Job Satisfaction & $-0.15^{* * *}$ & {$[-0.20,-0.09]$} & -0.06 & {$[-0.12,0.01]$} & -0.09 & {$[-0.12,-0.05]$} \\
Job Happiness & $-0.18^{* * *}$ & {$[-0.23,-0.12]$} & $-0.07^{*}$ & {$[-0.13,-0.02]$} & -0.10 & {$[-0.13,-0.08]$} \\
Neg. Work-Life & $0.41^{* * *}$ & {$[0.34,0.49]$} & $0.17^{* * *}$ & {$[0.10,0.25]$} & 0.24 & {$[0.19,0.30]$} \\
Balance & & & & & & \\
\hline
\end{tabular}

${ }^{*} \mathrm{p}<0.05 ;{ }^{* *} \mathrm{p}<0.05 ;{ }^{* *} \mathrm{p}<0.05 . \mathrm{B}=$ unstandardised coefficient; $\mathrm{CI}=$ confidence interval.

mediate the impact of job demands on life happiness, life satisfaction, and job satisfaction, with the direct effect reduced to non-significance, indicating full mediation. Fatigue was also found to mediate the impact of job demands on work-life balance and job happiness (i.e., happiness at work), with partial 
Table 4. Mediation effects of fatigue for positive personality on well-being outcomes.

\begin{tabular}{ccccccc}
\hline & \multicolumn{3}{c}{ X: Job Support and control } & \multicolumn{3}{c}{ M: Fatigue } \\
\cline { 2 - 7 } Y & \multicolumn{3}{c}{ Total Effects } & & Direct Effects & \multicolumn{2}{c}{ Indirect Effects } \\
\cline { 2 - 7 } & $B$ & $C I$ & $B$ & $C I$ & $B$ & $C I$ \\
\hline Life Satisfaction & $0.40^{* * *}$ & {$[0.35,0.45]$} & $0.37^{* * *}$ & {$[0.31,0.42]$} & 0.03 & {$[0.02,0.05]$} \\
Life Happiness & $0.36^{* * *}$ & {$[0.31,0.40]$} & $0.32^{* * *}$ & {$[0.280 .37]$} & 0.03 & {$[0.020 .05]$} \\
Job Satisfaction & $0.55^{* * *}$ & {$[0.50,0.60]$} & $0.52^{* * *}$ & {$[0.47,0.57]$} & 0.03 & {$[0.01,0.05]$} \\
Job Happiness & $0.53^{* * *}$ & {$[0.48,0.57]$} & $0.49^{* * *}$ & {$[0.44,0.57]$} & 0.04 & {$[0.03,0.06]$} \\
Neg0. Work-Life & $-0.37^{* * *}$ & {$[-0.45,-0.29]$} & $-0.22^{* * *}$ & {$[-0.30,-0.15]$} & -0.15 & {$[-0.20,-0.11]$} \\
Balance & & & & & & \\
\hline
\end{tabular}

mediation. The effect of job support and control on negative work-life balance and positive well-being were partially mediated by fatigue. These mediation effects were considered to be significant, as the confidence interval of indirect effects did not contain zero.

The results showed that fatigue partially mediated the impact of shift work on negative work-life balance. The total effect of demand on efficiency was 1.57 (C.I $=1.19,1.95, \mathrm{p}<0.001)$, with a direct effect of demand on efficiency of $1.19(\mathrm{CI}=$ $0.85,1.53, \mathrm{p}<0.001)$. The indirect effect was 0.39 , and the confidence interval was 0.22 to -0.58 , which was significant. No mediation was found between shift work and the other outcomes because those relationships were non-significant ( $p$ of total effect $>0.5$ ).

Fatigue partially mediated the influences of noise and fumes on negative work-life balance (see Table 5 and Table 6). The impact of these two work environmental factors were fully mediated by fatigue on job happiness and job satisfaction. As the impacts of noise and fumes on life satisfaction and life happiness were non-significant, there was no mediation effect.

\subsection{Comparing the Effect of Predictors in High/Low Fatigue Groups}

The individual scores for fatigue and predictors used in the following analysis were categorised as high or low using median split. For example, fatigue $(M=6$, range $=1$ to 10$)$ scores above the median were categorised as "high fatigue," while the others were categorised as "low fatigue". Eta-squared $\left(\eta^{2}\right)$ in ANOVA was used to compare the effects size of the predictor variables on the outcomes for the high/low fatigue groups. Cohen [19] classified 0.01 as a small effect, .06 as a medium effect and 0.14 as a large effect.

It was predicted that the beneficial effects of positive predictors would be smaller in the high fatigue group. For example, as Table 7 shows, the difference in the means for high/low social support on a positive outcome were bigger in the low fatigue group. Similarly, a positive predictor had a bigger effect on a 
Table 5. Mediation effects of fatigue for positive personality on well-being outcomes.

\begin{tabular}{ccccccc}
\hline & \multicolumn{3}{c}{ X: Exposure to noise } & \multicolumn{3}{c}{ M: Fatigue } \\
\cline { 2 - 7 } Y & \multicolumn{3}{c}{ Total Effects } & & Direct Effects & \multicolumn{2}{c}{ Indirect Effects } \\
\cline { 2 - 7 } & $B$ & $C I$ & $B$ & $C I$ & $B$ & $C I$ \\
\hline Job Satisfaction & $-0.05^{*}$ & {$[-0.09,-0.01]$} & -0.01 & {$[-0.05,-0.03]$} & -0.04 & {$[-0.05,-0.03]$} \\
Job Happiness & $-0.06^{*}$ & {$[-0.09,-0.02]$} & -0.01 & {$[-0.05,0.03]$} & -0.05 & {$[-0.06,-0.03]$} \\
$\begin{array}{c}\text { Neg0. Work-Life } \\
\text { Balance }\end{array}$ & $0.21^{* *}$ & {$[0.16,0.26]$} & $0.11^{* * *}$ & {$[0.06,0.16]$} & 0.10 & {$[0.08,0.13]$} \\
\hline
\end{tabular}

${ }^{*} \mathrm{p}<0.05 ;{ }^{* *} \mathrm{p}<0.05 ;{ }^{* * *} \mathrm{p}<0.05 . \mathrm{B}=$ unstandardised coefficient; $\mathrm{CI}=$ confidence interval.

Table 6. Mediation effects of fatigue for positive personality on well-being outcomes.

\begin{tabular}{cccccccc}
\hline & \multicolumn{3}{c}{ X: Exposure to fumes } & \multicolumn{3}{c}{ M: Fatigue } \\
\cline { 2 - 8 } Y & \multicolumn{3}{c}{ Total Effects } & & Direct Effects & \multicolumn{2}{c}{ Indirect Effects } \\
\cline { 2 - 8 } & $B$ & $C I$ & $B$ & $C I$ & $B$ & $C I$ \\
\hline Job Satisfaction & $-0.06^{* *}$ & {$[-0.10,-0.02]$} & -0.02 & {$[-0.06,-0.02]$} & -0.04 & {$[-0.05,-0.02]$} \\
Job Happiness & $-0.07^{* *}$ & {$[-0.11,-0.03]$} & -0.02 & {$[-0.06,0.01]$} & -0.04 & {$[-0.06,-0.03]$} \\
$\begin{array}{c}\text { Neg0. Work-Life } \\
\text { Balance }\end{array}$ & $0.24^{* *}$ & {$[0.19,0.29]$} & $0.15^{* *}$ & {$[0.10,0.19]$} & 0.09 & {$[0.07,0.12]$} \\
\hline
\end{tabular}

${ }^{*} \mathrm{p}<0.05 ;{ }^{* *} \mathrm{p}<0.05 ;{ }^{* *} \mathrm{p}<0.05 . \mathrm{B}=$ unstandardised coefficient; $\mathrm{CI}=$ confidence interval.

Table 7. Mean of outcomes by fatigue and job support.

\begin{tabular}{ccccc}
\hline \multirow{2}{*}{ Mean (SD) } & \multicolumn{2}{c}{ High Fatigue } & \multicolumn{2}{c}{ Low Job Fatigue } \\
\cline { 2 - 5 } & $\begin{array}{c}\text { High Job Support } \\
\text { and Control }\end{array}$ & $\begin{array}{c}\text { Low Job Support } \\
\text { and Control }\end{array}$ & $\begin{array}{c}\text { High Job Support } \\
\text { and Control }\end{array}$ & $\begin{array}{c}\text { Low Job Support } \\
\text { and Control }\end{array}$ \\
\hline Life Happiness & $7.92(1.54)$ & $7.03(1.73)$ & $8.61(1.17)$ & $7.27(1.78)$ \\
Life Satisfaction & $7.85(1.66)$ & $6.76(1.92)$ & $8.34(1.44)$ & $7.08(1.90)$ \\
Job Happiness & $8.06(1.41)$ & $6.52(2.06)$ & $8.79(1.12)$ & $6.99(1.79)$ \\
Job Satisfaction & $8.18(1.55)$ & $6.64(2.09)$ & $8.79(1.41)$ & $6.80(2.14)$ \\
Neg. Work-Life & $6.70(2.70)$ & $7.29(2.24)$ & $4.08(2.51)$ & $5.62(2.58)$ \\
Balance & & & &
\end{tabular}

$\mathrm{SD}=$ Standard Deviation

negative outcome (negative work-life balance) in the low fatigue group compared to those with high fatigue.

The results showed that the effect size of job support and control on all of the five well-being outcomes and the effect of job demands on work-life balance $\left(\eta_{\text {low fatigue group }}^{2}=0.04 ; \eta_{\text {high fatigue group }}^{2}=0.02\right)$ as larger in the low fatigue group than in the high fatigue group. In the low fatigue group, the effect size of job supports and control, calculated using eta squared was large on job happiness $\left(\eta^{2}\right.$ low fatigue group $\left.=0.29: \eta_{\text {high fatigue group }}^{2}=0.15\right)$, job satisfaction $\left(\eta_{\text {low fatigue group }}^{2}=0.24: \eta_{\text {high fatigue }}^{2}\right.$ group $=0.14)$, and life happiness $\left(\eta_{\text {low fatigue group }}^{2}=0.17 ; \eta_{\text {high fatigue group }}^{2}=0.07\right)$, and it was medium on life satisfaction $\left(\eta_{\text {low fatigue group }}^{2}=0.13\right.$ : $\left.\eta_{\text {high fatigue group }}^{2}=0.08\right)$, with 
all $\eta^{2}$ larger than those in the high fatigue group. Besides, the effect sizes of individual differences were larger in low fatigue group than in high fatigue group. For personality, the effect size was large on life happiness $\left(\eta_{\text {low fatigue group }}^{2}=0.34\right.$ : $\left.\eta_{\text {high fatigue group }}^{2}=0.15\right)$ and life satisfaction $\left(\eta_{\text {low fatigue group }}^{2}=0.25: \eta_{\text {high fatigue group }}^{2}=\right.$ 0.12). It was medium on job happiness and in job happiness in low fatigue group, which is still larger than in high fatigue group. For healthy behaviours, the effect size on the well-being outcomes was also larger in low fatigue group than in high fatigue group. The effect size of other predictor variables was not very different between high/low fatigue groups.

\section{Discussion and Conclusion}

The mediation effects found in this study are in line with what the DRIVE model proposed [12]. The hypothesis predicted that fatigue would mediate the impact of work characteristics and individual differences on well-being outcomes. This is an important prediction based on the enhanced DRIVE model, which proposes that perceived fatigue is the cognitive mechanism by which psychosocial stressors are transmitted into the well-being outcomes.

The correlation results showed that fatigue was significantly related to work-life balance and well-being, in both daily life and work life, included life satisfaction, life happiness, job satisfaction, and happiness at work. Job characteristics and personal characteristics were also significantly associated with fatigue and the outcomes, as previous studies have shown [1] [2] [3] [7] [8], while the work environment was not found to be significantly correlated with positive well-being outside work.

In the mediation analysis, fatigue was found to mediate the effects of individual differences and work characteristics on negative work-life balance and most of the positive well-being outcomes. In which case, full mediation effects of fatigue were found between lifestyle and negative work-life balance; between job demands and life happiness, life satisfaction, and job satisfaction; and between work environment (noise and fume) and well-being at work. This means that essentially all the relationships between the above variables were via the mediated or indirect pathway. Therefore, when considering the indirect pathway, the direct relationship becomes non-significant. For shiftwork, fatigue mediated its impact on negative work-life balance, meaning that shift-work increased fatigue, which then resulted in poor work-life balance. No significant direct effect was found for shiftwork on other well-being aspects. Noise and fumes in the workplace did not directly affect life satisfaction and life happiness.

The difference of outcomes between the high and low predictor groups (e.g., high/low support and control) was found bigger in the low fatigue group which was mainly because high fatigue removes the benefit of positive predictors. When compared the effect of the predictor variables on the outcomes for the high/low fatigue groups, the effect size of job supports and control and individual differences on positive well-being, and job demands for negative work-life 
balance was found larger in the low fatigue group. This indicated that high fatigue reduced the effect of predictors. In other words, there was the direct effect in the low fatigue group, while there were both the direct and indirect effect in the high fatigue group. These results supported the mediating role of fatigue between the predictors and well-being outcomes.

Overall, a large number of significant mediating effects of fatigue on the relationships between stressors and well-being outcomes were found, meaning that the hypothesis can be accepted. Thus, the results essentially support the enhanced DRIVE model.

This study examined the mediation effect of fatigue on the influences that job and personal characteristics have on negative work-life balance and positive well-being among UK railway staff. The results suggest that job characteristics and individual difference affect work-life balance and well-being, and that these effects can be mediated by fatigue. As a result, the process by which job demands influence positive well-being could be explained by fatigue. The results also provide support for the enhanced DRIVE model that fatigue was a mechanism through which job demands, job support, and control could affect well-being outcomes. In future studies, a healthy lifestyle can be considered as an intervention to decrease fatigue and, thus, improve work-life balance.

\section{Acknowledgements}

The authors would like to acknowledge the participants in the study for their support and assistance.

\section{References}

[1] Fan, J. and Smith, A.P. (2017) The Impact of Workload and Fatigue on Performance. H-Workload 2017: 1 st International Symposium on Human Mental Workload: Models and Applications, Dublin, 28-30 June 2017. https://doi.org/10.1007/978-3-319-61061-0_6

[2] Williams, G.M. and Smith, A.P. (2016) Using Single-Item Measures to Examine the Relationships Between Work, Personality, and Well-Being in the Workplace. Psychology: Special Edition on Positive Psychology, 7, 753-767. https://doi.org/10.4236/psych.2016.76078

[3] Chay, Y.W. (1993) Social Support, Individual Differences and Well-Being: A Study of Small Business Entrepreneurs and Employees. Journal of Occupational and Organizational Psychology, 66, 285-302. https://doi.org/10.1111/j.2044-8325.1993.tb00540.x

[4] DeNeve, K.M. and Cooper, H. (1998) The Happy Personality: A Meta-Analysis of 137 Personality Traits and Subjective Well-Being. Psychological Bulletin, 124, 197-229. https://doi.org/10.1037/0033-2909.124.2.197

[5] Smith, A.P. and Smith, H.N. (2017) A Short Questionnaire to Measure Wellbeing at Work (Short-SWELL) and to Examine the Interaction Between the Employee and Organisation. Proceedings of the Contemporary Ergonomics and Human Factors 2017. Staveton Estate, Daventry, Northamptonshire, 25-27 April 2017, 20-205.

[6] Smith, A.P. and Smith, H.N. (2017) An International Survey of the Wellbeing of 
Employees in the Business Process Outsourcing Industry. Psychology, 8, 160-167. https://doi.org/10.4236/psych.2017.81010

[7] Grant-Vallone, E.J. and Donaldson, S.I. (2001) Consequences of Work-Family Conflict on Employee Well-Being over Time. Work \& Stress, 15, 214-226. https://doi.org/10.1080/02678370110066544

[8] Fan, J. and Smith, A.P. (2017) Positive Well-Being and Work-Life Balance among UK Railway Staff. Open Journal of Social Sciences, 5, 1-6. https://doi.org/10.4236/jss.2017.56001

[9] Jackson, H. and MacLeod, A.K. (2017) Well-Being in Chronic Fatigue Syndrome: Relationship to Symptoms and Psychological Distress. Clinical Psychology \& Psychotherapy, 24, 859-869. https://doi.org/10.1002/cpp.2051

[10] Schwartz, A.L. (1999). Fatigue Mediates the Effects of Exercise on Quality of Life. Quality of Life Research, 8, 529-538. https://doi.org/10.1023/A:1008978611274

[11] Cameron, C. (1973) A Theory of Fatigue. Ergonomics, 16, 633-648. https://doi.org/10.1080/00140137308924554

[12] Mark, G.M. and Smith, A.P. (2008) Stress Models: A Review and Suggested New Direction. Occupational Health Psychology, 3, 111-144.

[13] Mark, G. and Smith, A.P. (2012) Effects of Occupational Stress, Job Characteristics, Coping, and Attributional Style on the Mental Health and Job Satisfaction of University Employees. Anxiety, Stress \& Coping, 25, 63-78. https://doi.org/10.1080/10615806.2010.548088

[14] Mark, G. and Smith, A.P. (2012) Occupational Stress, Job Characteristics, Coping, and the Mental Health of Nurses. British Journal of Health Psychology, 17, 505-521. https://doi.org/10.1111/j.2044-8287.2011.02051.x

[15] Williams, J. and Smith, A.P. (2013) Stress, Job Satisfaction and Mental Health of NHS Nurses. Contemporary Ergonomics and Human Factors, 95-102. https://doi.org/10.1201/b13826-22

[16] Capasso, R., Zurlo, M.C. and Smith, A.P. (2016) Ethnicity, Work-Related Stress and Subjective Reports of Health by Migrant Workers: A Multi-Dimensional Model. Ethnicity \& Health, 1-20.

[17] Hayes, A.F. (2017) Introduction to Mediation, Moderation, and Conditional Process Analysis: A Regression-Based Approach. Guilford Press, New York.

[18] Shrout, P.E. and Bolger, N. (2002) Mediation in Experimental and Nonexperimental Studies: New Procedures and Recommendations. Psychological Methods, 7, 422-445. https://doi.org/10.1037/1082-989X.7.4.422

[19] Cohen, J. (1988) Statistical Power Analysis for the Behavioral Sciences. 2nd Edition, Lawrence Erlbaum Associates, Hillsdale, 284-287. 